\title{
The impact of tool point angle and interlayer gap width on interface borehole quality in drilling CFRP/titanium stacks
}

\author{
Andrea Pardo ${ }^{1} \cdot$ Julie Le Gall $^{1} \cdot$ Robert Heinemann $^{1} \cdot$ Luke Bagshaw $^{2}$ \\ Received: 17 November 2020 / Accepted: 1 February 2021 / Published online: 10 March 2021 \\ (C) The Author(s) 2021
}

\begin{abstract}
Although substantial research work has been conducted in order to understand and improve the drilling of multi-material aerospace stacks, some key aspects related to process and tool parameters and their impact on the interface quality still need to be addressed. This paper reports on the research conducted to investigate the impact of tool point angle and interlayer gap width on borehole quality, focussing on the interface region. A number of drilling tests were carried out using tools with different point angles and CFRP/titanium stacks with different interlayer gap widths. The results show that the damage on the CFRP interlayer surface is caused by the drilling of the titanium layer, as some of the upwards-travelling titanium chips penetrate into the stack interface. An increase in tool point angle results in larger entry burrs on the titanium interlayer surface, which is attributed to the correlation between tool point angle and thrust force and the capability of tools with low point angles to remove damage generated by surface skidding. The introduction of an interlayer gap promotes the ingress of titanium chips into the stack interface, thereby leading to more pronounced interface damage.
\end{abstract}

Keywords Stack drilling $\cdot$ Hole quality $\cdot$ Stack interface $\cdot$ Tool point angle $\cdot$ Interlayer gap $\cdot$ Surface integrity

\section{Introduction}

In the aerospace industry, stacked structures comprising layers made of different materials, most commonly carbon fibrereinforced polymers (CFRP), aluminium and titanium, are gaining popularity due to their advantageous mechanical and

\section{Highlights:}

- Drilling one of the most challenging stack combinations in the aerospace industry

- Drilling CFRP/Ti stacks with tools exhibiting a wide range of tool point angles

- Drilling CFRP/Ti stacks with accurately pre-set interlayer gap widths

- Identification of damage in CFRP due to titanium chip flow and interface ingress

- Establishing relationship between interlayer gap width and CFRP interface damage

Robert Heinemann

robert.heinemann@manchester.ac.uk

1 Department of Mechanical, Aerospace and Civil Engineering, The University of Manchester, Sackville Street, Manchester M1 3BB, UK

2 Airbus Operations Limited, Chester Road, Broughton, Chester CH4 ODR, UK physical properties when compared with traditional singlemetal structures. Stacks comprising CFRP and titanium are particularly popular as they offer high strength-to-weight ratio and erosion resistance and, when compared with CFRP/aluminium stacks, reduced galvanic corrosion [1].

The assembly of multi-material stacks is commonly carried out using a large number of fasteners (i.e. bolts or rivets), for which the machining of an equally large number of boreholes is required. During the drilling operation, the layers that form the stack are usually clamped together and then machined in a single shot, to reduce positional errors and improve productivity [2]. In the case of CFRP/titanium stacks, this is often challenging due to the very different properties of the two materials. When drilling the composite layer, the low degradation temperature of the polymer matrix and modest bonding strength of the plies can result in heat-related damage and delamination [3-5]. In contrast, cutting of the titanium layer is often characterised by very high cutting temperatures and rapid tool wear, as a result of the material's low thermal conductivity and high chemical affinity to most of the tool materials used today $[6,7]$. The different characteristics of the two materials also result in different wear mechanisms taking place within a drilling cycle: abrasive wear and edge chipping when cutting CFRP [8-10], workpiece material adhesion and flank wear when cutting titanium $[6,9]$. 
Drilling of CFRP/titanium stacks has been the focus of extensive research in recent years. Xu and Mansori [11] carried out experiments to determine factors affecting the drilling of CFRP/ titanium stacks. They observed that tool features such as chisel edge length, point angle and helix angle play a more dominant role in the resulting borehole quality and tool life than tool substrate and coating. They also identified the evacuation of hot titanium chips as one of the major problems, as it can lead to chip clogging and premature tool failure as well as abrasion of the composite section of the already drilled borehole. To address this, the authors recommend using high feed rates in order to generate short segmented titanium chips, which are more easily evacuated. They also suggest arranging the stack with the titanium being the first layer to be machined, so that the titanium chips do not have to be evacuated through the CFRP layer, which would prevent any abrasion damage on the composite borehole surface. It is pertinent to note that the combination of their suggestions, i.e. high feed rate and placing the titanium as the entry layer, brings about a significant disadvantage, which is that the delamination of the CFRP would be exacerbated by the increase in downwards thrust force, due to high feed rate, and the lack of backing typically provided by the titanium layer placed underneath. When $\mathrm{Xu}$ et al. [12] investigated the impact of low frequency vibration assisted drilling when machining CFRP/ titanium stacks, they observed a major reduction in the mechanical and thermal load and improvement in the chip evacuation, which the authors attributed to the smaller chips produced. Similar research conducted by Li et al. [13] made the authors arrive at the same conclusions, but due to the use of chip suction, they also noticed an increase in oxidation wear, which the authors believed to be the result of the enhanced air flow through the chip flutes. Alonso et al. [14] assessed the impact of stepped tool geometries and number of chip flutes when drilling CFRP/ titanium stacks and found that tools exhibiting a stepped geometry and three flutes are less effected by tool wear than nonstepped, two-fluted drills. They reported a positive correlation between tool wear and resulting exit burr height in the titanium layer. This is due to the increasing roundness of the cutting edges and outer cutting edge corner, which the authors argue affects both the heat generation and shearing of the titanium material, hence promoting material flow and burr formation. Xu et al. [15] assessed the impact of through-tool minimum quantity lubrication (MQL) when drilling CFRP/titanium stacks. According to their findings, the use of MQL results in substantial improvements in terms of composite borehole surface morphology (reduced fibre pull-out and fibre/matrix debonding) and reduces the extent of tool wear, but does not affect the thrust force and, consequently, the delamination damage. When drilling titanium/CFRP/aluminium stacks, Kuo et al. [16] found uncoated carbide drills to exhibit a longer tool life than TiAlN/TiNcoated drills, which they attributed to the smaller cutting edge radius (i.e. sharper cutting edges) of the uncoated tools. However, the uncoated drills were found to produce boreholes of less accurate diameter, which the authors believed to be the result of more extensive wear at the tool periphery.

Drilling of the interface region between two stack layers is considered to be a highly complex operation due to the multi-tool work interaction, especially in the case of CFRP/titanium stacks [17]. Two factors directly affecting interface drilling are the tool's point angle and the interlayer gap width, as these determine the distance over which the drill's cutting edges are simultaneously engaged in both the materials. The impact of tool geometry on drilling of single-layer composite materials is reported by a number of authors, both with regards to GFRP [18-20] and CFRP [21-23]. With regards to the tool point angle, Gaitonde et al. [22] and Heisel and Pfeifroth [23] assessed carbide tools with point angles ranging from $85^{\circ}$ to $135^{\circ}$ and from $155^{\circ}$ to $185^{\circ}$, respectively, when drilling single-layer CFRP, and both observed that larger point angles resulted in more extensive exit delamination. However, since $\mathrm{Xu}$ and Mansori [11] observed that the presence of a metallic layer can affect the resulting composite borehole quality, to different extents depending on the stacking order, the observations made by Gaitonde et al. and Heisel and Pfeifroth may not be directly applicable to the drilling of CFRP/titanium stacks. With regards to the interlayer gap width, its impact on the formation of burrs protruding from metal layers into the stack interface has been researched extensively [24-29], but its impact on other important borehole quality indicators, such as edge condition, surface roughness and borehole diameter, is still not fully understood.

The review of the literature suggests that, although substantial research work has been devoted to the understanding and improving of the drilling of multi-material aerospace stacks, some key aspects still need to be addressed, in particular the cutting and resulting quality of the interface between stack layers comprising different materials. This paper therefore reports on the research work conducted to investigate the impact of tool point angle and interlayer gap width on borehole quality, with a focus at the interface region. For this, a number of drilling tests were carried out using tools with different point angles $\left(118^{\circ}\right.$ to $\left.180^{\circ}\right)$ and stacks exhibiting interlayer gaps of different widths $(0.05 \mathrm{~mm}$ to $0.3 \mathrm{~mm})$.

\section{Experimental methodology}

\subsection{Experimental setup}

The experiments were carried out on CFRP/titanium stacks, with the CFRP layer on top (i.e. entry layer). The properties of the two materials are listed in Table 1. For the drilling tests, the stacks were provided as coupons with a size of $50 \mathrm{~mm} \times 50$ $\mathrm{mm}$. The use of larger plates as workpiece material, despite being more representative of aerospace manufacturing processes, would have caused a significant loss of control over the clamping force applied to the stack at different borehole 
Table 1 Ti-6Al-4V and CFRP specifications

\begin{tabular}{ll}
\hline Ti6Al4V & \\
\hline Condition & Annealed \\
\hline Chemical composition (\%wt) & Ti 87.6-91 Al 5.5-6.75 V 3.5-4.5 \\
& $\mathrm{Fe}<0.25 \mathrm{O}<0.2 \mathrm{C}<0.08 \mathrm{~N}<0.05$ \\
Tensile strength & $950 \mathrm{MPa}$ \\
Thermal conductivity & $7.0 \mathrm{~W} /(\mathrm{mK})$ \\
CFRP & \\
Manufacturing method & Autoclave cured \\
Stacking sequence & {$\left[45^{\circ}, 135^{\circ}, 0^{\circ}, 0^{\circ}, 45^{\circ}, 135^{\circ}, 0^{\circ}, 0^{\circ}, 90^{\circ}, 0^{\circ}\right]_{4 \mathrm{~s}}$} \\
Nominal ply thickness & $0.254 \mathrm{~mm}$ \\
Number of plies & $40[\mathrm{enclosed}$ within two M21/1080 glass cured plies]
\end{tabular}

locations. This would have resulted in significant variations in the interlayer gap thickness during different drilling cycles [28], which would have made it difficult to establish a relationship between tool point angle and interlayer borehole quality [24]. It is pertinent to note though that the fundamental information gathered can be directly applied to the drilling of larger components.

The thicknesses of the CFRP throughout all experiments was $10.4 \mathrm{~mm}$; the thickness of the titanium layer was $10 \mathrm{~mm}$ for the first set of experiments, where the focus was on the impact of tool point angle on interlayer borehole quality and $5 \mathrm{~mm}$ for the second set, which focussed on the impact of interlayer gap size on interlayer damage. The motivation for reducing the thickness originated from previous research, where it was observed that the presence of very large interlayer gaps (in excess of $0.1 \mathrm{~mm}$ ) resulted in substantial damage at the interface [24]. Bearing in mind that the previous research was carried out on aluminium/aluminium stacks, it was assumed that the drilling of CFRP/titanium stacks would have led to significantly more damage, as a result of the softer nature of the entry layer, in this case CFRP, and the considerably harder and more abrasive nature of the chips produced when drilling into the lower layer, in this case titanium. In order to limit the abrasion of the CFRP by the titanium chips and thus prevent excessive damage to occur on the entry layer, it was decided to significantly reduce (by 50\%) the amount of titanium chips flowing through the existing borehole by halving the thickness of the titanium layer to $5 \mathrm{~mm}$.

The drilling jig for this research work is shown in Fig. 1. A custom-made vice comprising a lower steel base ('vice rest') and an aluminium frame containing a square cut-out ('vice frame') was used to clamp the coupons by tightening two M8 screws. Throughout the experiments, the coupons were clamped together with a load of $2 \mathrm{kN}$ per screw. The vice rest allowed the bottom layer of the stack to rest on a 5-mm-wide shoulder on either side, leaving a $40 \mathrm{~mm}$ wide strip below the centre of the stack to permit breakthrough of the drill. The clamping fixture was mounted on a Kistler 9271A piezo-electric dynamometer, connected to a charge amplifier (Kistler 5006). The outputs were recorded with a sampling frequency of $1 \mathrm{kHz}$ by a data acquisition card (NI 6356) connected to a computer running Labview as the data acquisition software.

\subsection{Drilling experiments}

Two sets of experiments were carried out. In the first set, 6$\mathrm{mm}$ diameter two-fluted tungsten carbide twist drills with four different geometries were used. The specifications of these are listed in Table 2, and Fig. 2 shows images of their tip geometries. These tool geometries were selected in order to cover the widest possible range of point angles whilst maintaining other important geometric features as closely as possible. Although geometry B does not exhibit notches, it has a sixfacet cut that provides clearance adjacent to the chisel edge, which can be considered equivalent to the notches of the other three geometries. The differences in both helix/rake and flank angle are within $1.5^{\circ}$ and $4^{\circ}$, respectively, the latter being of low significance in this drilling process because of the low feed rate values used. Based on the observations made by Shyha et al. [30], the different coating conditions of the tools employed are believed to not have an impact on borehole quality. For each tool geometry, three drills were used. Throughout the tests, not only was tool usage limited to a maximum of 9 boreholes, thereby ensuring that the maximum extent of tool wear was negligible and, thus, did not noticeably affect the cutting performance, but the extent of tool wear was also regularly checked using an optical microscope (Jenoptik C10 Plus). For reasons of comparability, it was decided to run all drilling tests with one set of cutting parameters, see Table 3. This set of parameters was arrived at by taking into account the individual parameters for each tool provided by the tool manufacturer, as well as parameters used in previous research $[11,30]$. 
Fig. 1 Experimental setup

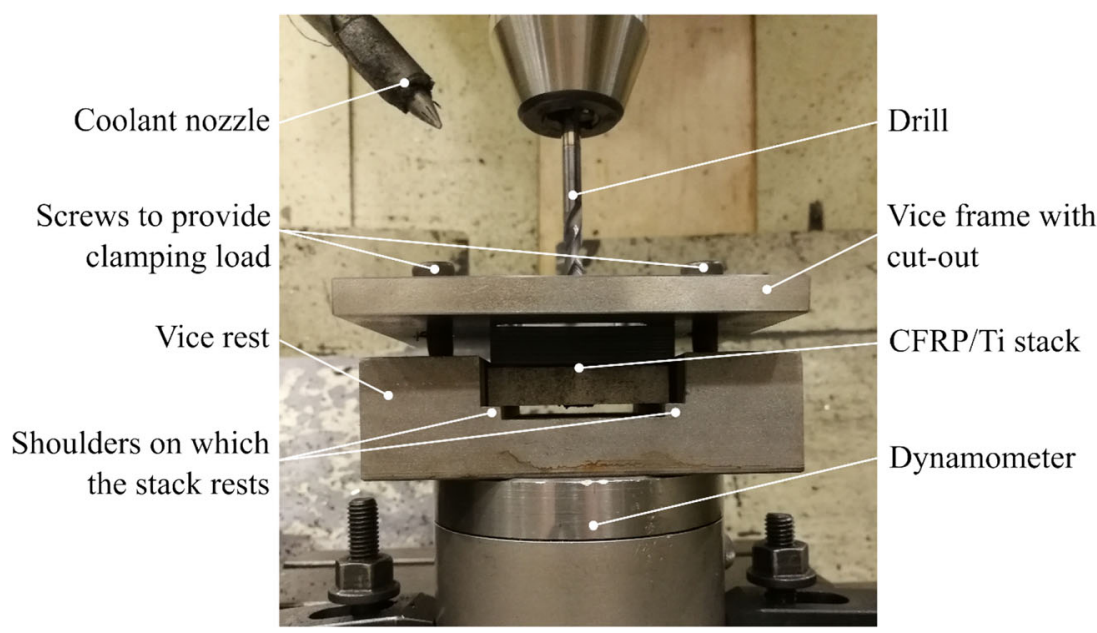

In the second set of experiments, metal shims (i.e. thin metal strips used as spacers) were placed in the stack interface to create an interlayer gap, which is known to form in industrial applications as a result of the bending of the layers under the drill thrust and the presence of sealant at the stack interface. The employment of shims allowed for the setting of predefined interlayer gap widths whilst preventing any variation of these during the drilling cycle. Four different interlayer gap widths commonly found in aerospace stack drilling [24] were defined, by using shims of thicknesses $0.05 \mathrm{~mm}, 0.1 \mathrm{~mm}$, $0.2 \mathrm{~mm}$ and $0.3 \mathrm{~mm}$. Tools of type $\mathrm{B}\left(140^{\circ}\right.$ point angle $)$ were used for these tests, as they were found to result in the most stable cutting process during the first set of experiments.

The cutting experiments were carried out on a three-axis vertical machining centre (Takisawa MAC-V3). Twelve holes arranged in a four-by-three matrix were drilled into each coupon, with a pitch between adjacent boreholes of $9 \mathrm{~mm}$, which resulted in a wall thickness of $3 \mathrm{~mm}$. All tests were conducted using external coolant supply. Table 3 provides a summary of the experimental parameters.

\subsection{Borehole quality measurements}

When drilling CFRP/titanium stacks, interface damage was reported to appear in the form of discolouration/damage rings, delamination and fibre pull out in the composite surface [17, 31 ], and in the form of entry interlayer burrs in the titanium surface [32]. Two different procedures were thus employed to assess the interface damage in the two materials. With regards to the CFRP, images were taken with an optical microscope (Jenoptik Progress C10 Plus) and the damage factor was determined as the ratio between the maximum extent of any visible damage and the nominal borehole diameter. The interlayer burr on the titanium surface was measured using a contactless profilometer (Nanofocus $\mu$ scan), which performed two line scans across the centre of the borehole, at $0^{\circ}$ and $90^{\circ}$, thereby measuring the burr height in four locations, i.e. $0^{\circ}, 90^{\circ}, 180^{\circ}$ and $270^{\circ}$. In the titanium layer, the borehole diameter and surface roughness were measured with a coordinate measuring machine (LK G90C, Renishaw TP20 touch trigger probe, 7 touch points) and a surface roughness tester (Hommel Waveline W5, Probe T1E, $2 \mu \mathrm{m} / 90^{\circ}$, $8 \mathrm{~mm}$ scan length, at $0^{\circ}$ and $180^{\circ}$ ), respectively. It was decided not to determine the borehole diameter and surface finish with regards to the CFRP layer, as the presence of hard fibres sticking out into the borehole would have led to fictitious results [33].

\section{Results and discussion}

\subsection{Influence of tool point angle on CFRP interface quality}

The results of the first set of experiments, which was concerned with establishing relationships between the tool point

Table 2 Specifications of various tool geometries employed

Tool geometry Reference number Point angle Helix angle Rake angle Flank angle Coating Chip flute geometry Point geometry

\begin{tabular}{lcccccccc}
\hline A & A1163-6 & $118^{\circ}$ & $31.5^{\circ}$ & $31.5^{\circ}$ & $7^{\circ}$ & None & Enlarged & Four-facet with notches \\
B & A3899XPL-6 & $140^{\circ}$ & $30^{\circ}$ & $30^{\circ}$ & $6^{\circ}$ & XPL & Standard & Six-facet \\
C & A6181TFT-6 & $150^{\circ}$ & $30^{\circ}$ & $30^{\circ}$ & $6^{\circ}$ & TFT & Enlarged & Four-facet with notches \\
D & A7191TFT-6 & $180^{\circ}$ & $30^{\circ}$ & $30^{\circ}$ & $10^{\circ}$ & TFT & Enlarged & Four-facet with notches \\
\hline
\end{tabular}


Fig. 2 Tool tip geometries used in the drilling tests; $\mathbf{a}$ tool $\mathrm{A} ; \mathbf{b}$ tool $\mathrm{B} ; \mathbf{c}$ tool $\mathrm{C} ; \mathbf{d}$ tool D
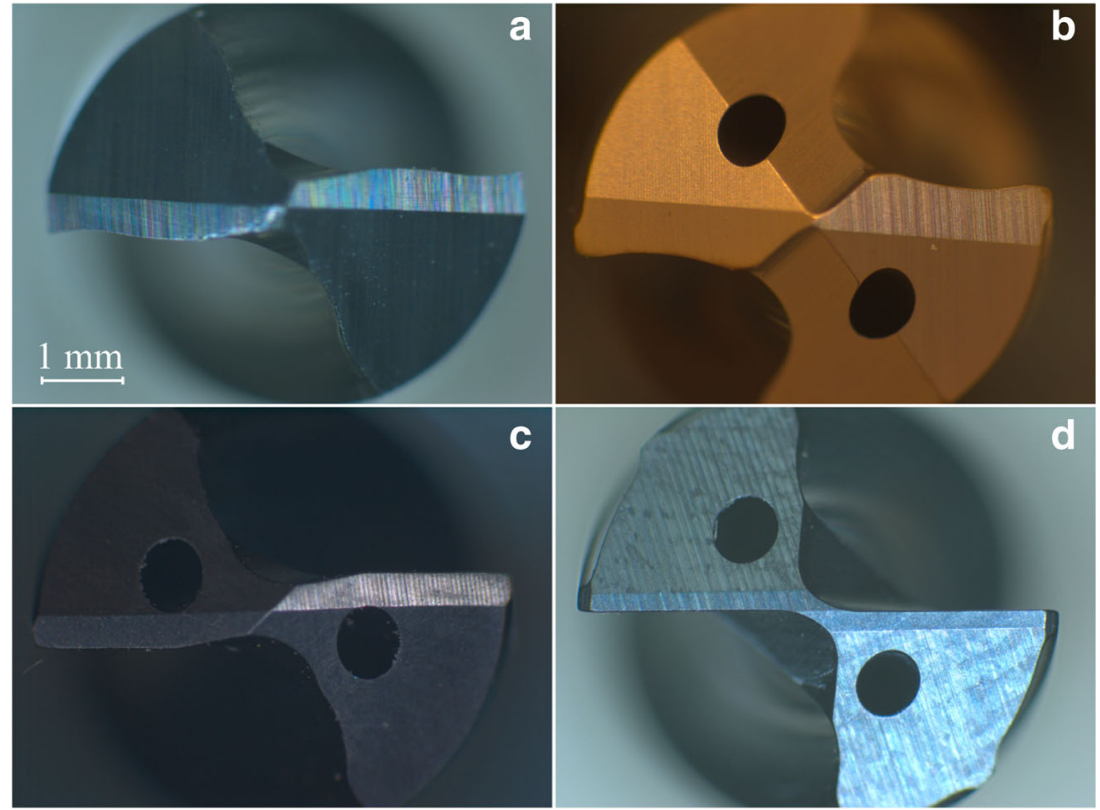

angle and the stack interface surface quality, are presented in Figs. 3, 4, 5, 6, 7, 8, 9 and 10. Figure 3 shows a typical example of the interlayer (i.e. exit) surface of the CFRP layer, for the four different tool geometries under investigation.

The first observation to be made is that the width of the damage zone around the borehole is fairly uniform, regardless of the tool geometry. This is in contrast to drilling single layer unidirectional CFRP, where the damage zone typically exhibits a skewed shape, with the main extension in the direction of the fibres, as observed by Fu et al. [34]. Moreover, the appearance of the damage is noticeably different to that resulting from drilling single layer CFRP, so much so that the colour of the damage zone indicates the occurrence of thermal degradation rather than mechanical damage, e.g. delamination or fibre pull-out.

This observation can be explained by the fact that the majority of the damage noticed in this experiment is not caused by the cutting of the CFRP, but is a result of three phenomena related to the subsequent drilling of the titanium layer underneath the CFRP. Firstly, as observed by both Xu and Mansori

Table 3 Experimental parameters

\begin{tabular}{ll}
\hline Cutting speed & $40.5 \mathrm{~m} / \mathrm{min}$ \\
\hline Feed rate & $0.1 \mathrm{~mm} / \mathrm{rev}$ \\
Coolant & Blaser Blasocut BC $25 \mathrm{MD}$ \\
Coolant pressure & $2 \mathrm{bars}$ \\
Coolant Flow rate & $2 \mathrm{1} / \mathrm{h}$ \\
Clamping load & $2 \mathrm{kN}$ \\
Interlayer gap $(\mathrm{mm})$ & $0 ; 0.05 ; 0.1 ; 0.2 ; 0.3$ \\
\hline
\end{tabular}

[11] and Brinksmeier and Janssen [35], the upwards-travelling titanium chips not only cause extensive erosion due to their shape and serrated edges, as evidenced by the chip samples shown in Fig. 4, but they also contribute to thermal damage, as part of the heat stored within the chips is released to the CFRP layer surrounding the tool. Secondly, the cutting heat generated when the drill begins to engage in the titanium layer, illustrated as stage 1 in Fig. 5, does not disperse into the titanium due to its poor thermal conductivity, but instead accumulates at the stack interface. A portion of this heat then migrates into the CFRP layer, thereby causing thermal softening and degradation of the matrix. The relatively higher thermal conductivity of the tool material $(80 \mathrm{~W} / \mathrm{mK}$ for cemented tungsten carbide, as opposed to $7 \mathrm{~W} / \mathrm{mK}$ for titanium) makes it likely that the cutting tool provides an additional passage way for some of the cutting heat to migrate into the CFRP. Once the drill tip is fully engaged in the titanium layer, illustrated as stage 2 in Fig. 5, a significant portion of the cutting heat is still transferred into the underside of the CFRP layer, both via the tool and directly at the periphery of the borehole. Lastly, as a result of the high temperatures generated when drilling the titanium, the tool experiences thermal expansion, which causes its margins to progressively rub over the already drilled CFRP borehole surface, thus promoting both abrasive and thermal damage.

To provide further evidence for the aforementioned explanations, a number of boreholes were drilled into a CFRP/CFRP stack, where the tool was retracted once its cutting edges had fully broken through the upper layer. This scenario was designed in order to replicate that part of the CFRP/titanium stack drilling process where the drill is only engaged with the top CFRP layer, thereby eliminating any detrimental effect that could arise from 


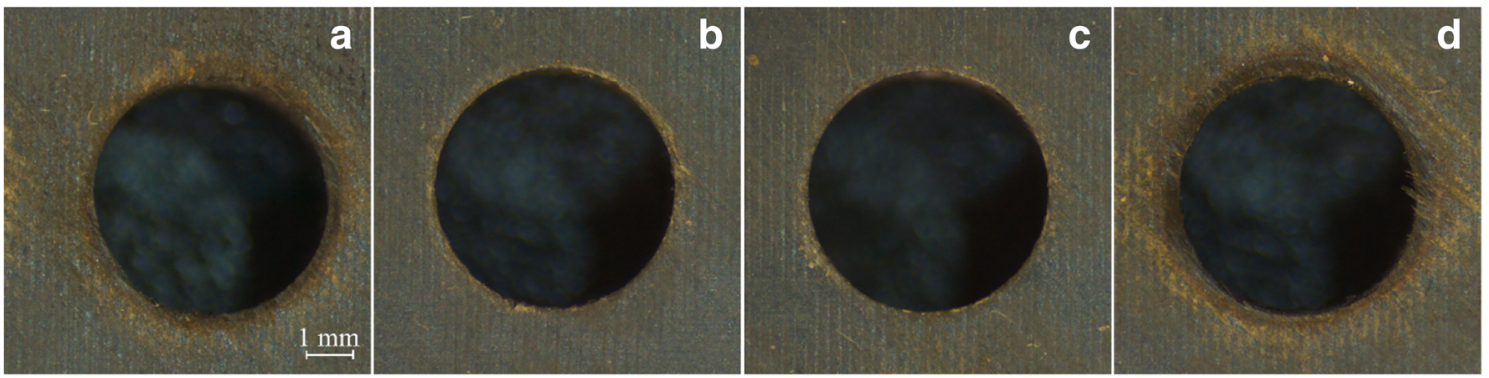

Fig. 3 CFRP interface damage for the tool geometries assessed; $\mathbf{a}$ tool A; $\mathbf{b}$ tool B; $\mathbf{c}$ tool C; $\mathbf{d}$ tool D

the drill's engagement with the bottom titanium layer, whilst at the same time providing support to the top CFRP layer. The bottom surfaces of the boreholes drilled with this setup, two of which are shown in Fig. 6, exhibit damage whose width is not uniform but instead extends in the direction of the fibres (at $45^{\circ}$ in this case). Moreover, the damage area does not show any of the scratch or burn marks observed when drilling CFRP/titanium stacks, thus providing evidence that the thermal damage observed in Fig. 3 is to be attributed to the drilling of the lower titanium layer.

A second observation that can be made in connection with Fig. 3 is that the boreholes drilled with tools A $\left(118^{\circ}\right.$ point angle) and $\mathrm{D}\left(180^{\circ}\right.$ point angle) exhibit significantly larger composite interface surface damage than those drilled with tools $\mathrm{C}\left(150^{\circ}\right.$ point angle $)$ and, to a slightly larger extent, tools $\mathrm{B}\left(140^{\circ}\right.$ point angle). The corresponding damage factors were found to be 1.29, 1.14, 1.16 and 1.50 for tool geometries A, B, $\mathrm{C}$ and $\mathrm{D}$, respectively.

Gaitonde et al. [22] observed that an increase in point angle leads to an increase in exit damage when drilling CFRP, which they attribute to the higher thrust force. This is in agreement with Heisel and Pfeifroth [23], who add that the rise in thrust force is caused by an increase in chip thickness, which is a result of the greater point angle. With regards to this research, looking at the results obtained from tools B, C and $\mathrm{D}$, the difference in the extent of damage on the CFRP layer at the stack interface is in agreement with Heisel and Pfeifroth and Gaitonde et al., inasmuch as an increase in tool point angle
Fig. 4 Titanium chips formed by different tool geometries; a tool $\mathrm{B} ; \mathbf{b}$ tool $\mathrm{C} ; \mathbf{c}$ tool A; $\mathbf{d}$ tool D

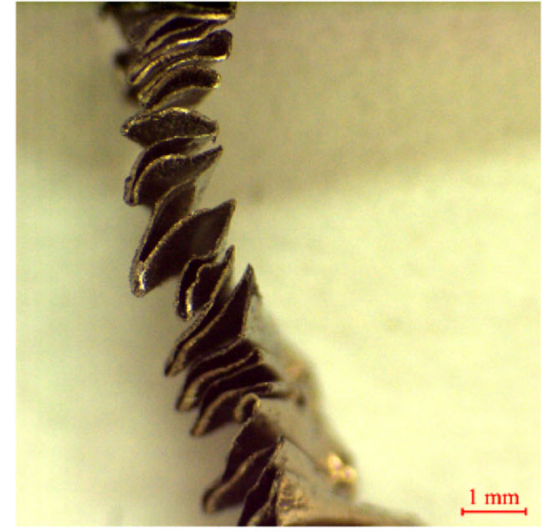

a

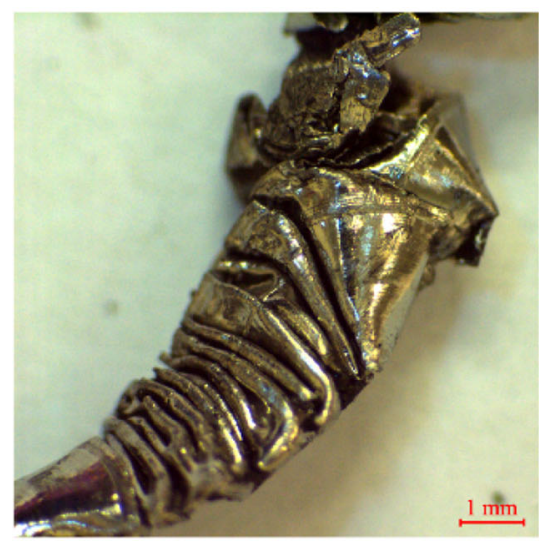

C

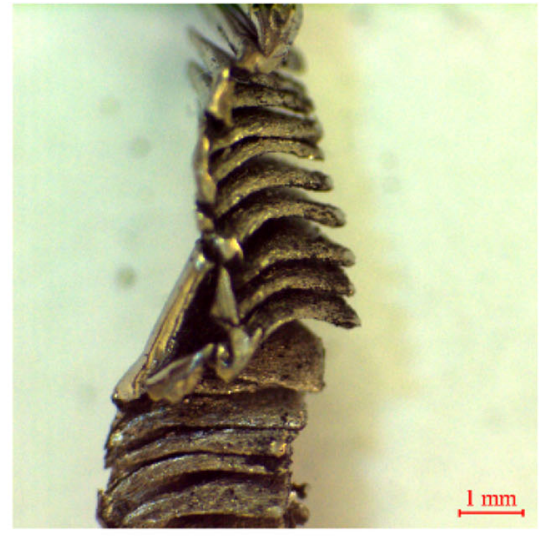

b

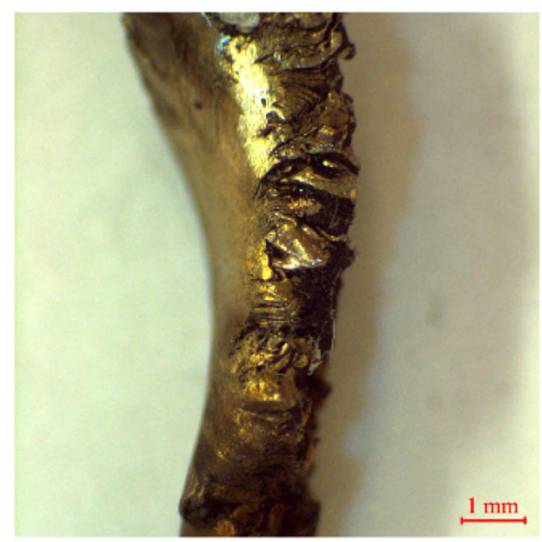

d 


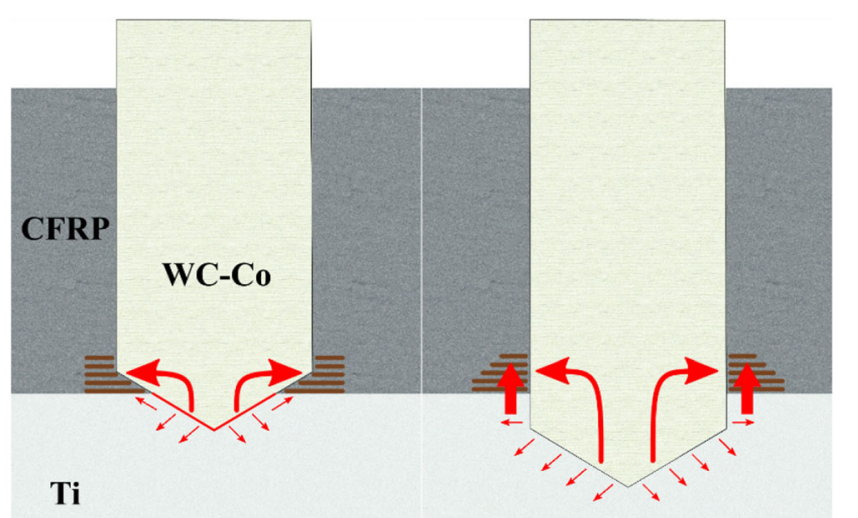

Stage $1 \quad$ Stage 2

Fig. 5 Accumulation of cutting heat at CFRP interface and heat migration from the titanium layer into the CFRP layer

increases the size of damage. However, tools A do not follow this trend, as the damage recorded is significantly larger than that observed for tools B and C. This suggests that another process must be affecting the outcome.

Since the research conducted by Heisel and Pfeifroth and Gaitonde et al. was only concerned with drilling single layer CFRP, the results obtained from this research indicate that the introduction of a titanium layer underneath the CFRP has a profound impact on the interlayer borehole quality. This can be related to the fact that the drilling of titanium is characterised by the generation of considerable heat energy that, as a result of the material's poor thermal conductivity, remains in the vicinity of the borehole. Part of this heat, as alluded to before, migrates into the CFRP layer, where it causes substantial thermal damage.

The tool point angle directly affects the amount of cutting heat generated, inasmuch that a decrease in tool point angle results in an increase in the length of the drill's cutting edges and, consequently, an increase in the drilling torque and cutting temperature. Further to this, the tool point angle also affects the chip shape, which again is attributable to the change in cutting edge length. An increase in the tool point angle will reduce

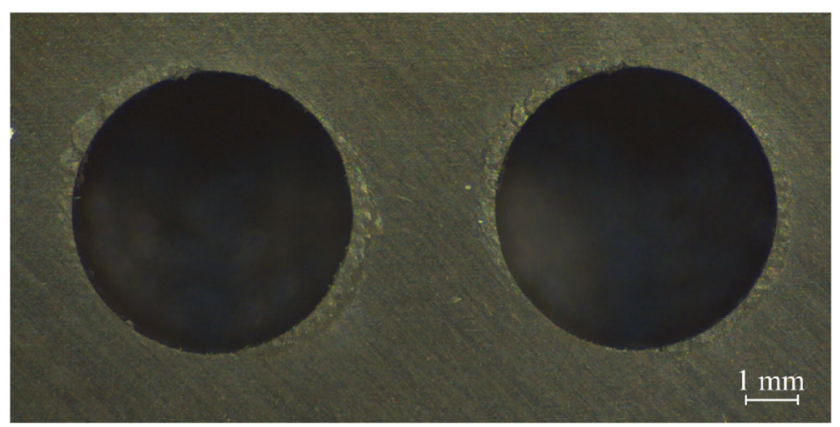

Fig. 6 Interface damage on the entry layer of CFRP/CFRP stack chip width but increase chip thickness, whereas a decrease will lead to a thinner but wider chip. The images taken of the chips extracted from the borehole, as well as the torque signals recorded, clearly demonstrate that both extremes, i.e. very wide but thin as well as narrow and thick chips, are difficult to evacuate from the borehole through the drill's chip flutes. The shapes of the chips collected when using tools B and C, Fig. 4 a and b, exhibit a typical shape, characterised by a relatively loose fold-up. In contrast, the chips collected when using tools A and D, see Fig. $4 \mathrm{c}$ and d, exhibit either a much tighter fold-up or are even severely crushed and/or compressed, which provides evidence that these chips were exposed to substantial compressive forces during the evacuation process through the drill's flutes. The recorded torque curves, see Fig. 7, show a smooth and stable torque amplitude for tools $\mathrm{B}$ and $\mathrm{C}$, suggesting that the flow of chips was hardly obstructed, whereas in the case of tools A and D, a strong rise in amplitude combined with a rise in fluctuation towards the latter part of the drilling through the titanium layer indicates significant chip jamming. As a consequence of the obstructed chip flow, a relatively larger part-compared with the scenario characterised by a smooth chip flow-of the amount of heat stored within the chips was released to their surroundings, which was the tool and the neighbouring borehole material, the upper part of which was CFRP. Moreover, the obstructed chip flow, due to the strong friction between chip, tool and borehole, will have caused additional heat to be generated, thereby further increasing the thermal damage on the CFRP layer.

An example of the typical cutting forces recorded during the experiments is shown in Fig. 7. For all the assessed tools, the thrust force and torque produced when drilling CFRP were found to be significantly lower than those recorded when drilling titanium, which can be attributed to the softness of the former and the, therefore, lower cutting energy required for material removal. The results also show that tools exhibiting smaller point angles generated a larger cutting torque, which is the result of the increase in cutting edge length with decreasing point angle. It was also observed that the change in cutting forces during transition from CFRP to titanium becomes more abrupt as the drill point angle increases. This is due to the fact that larger point angles result in shorter interface drilling times, which is the time during which the tool's cutting edges are simultaneously engaged in the cutting of both the upper and lower layer (see Fig. 5, stage 1) and, thus, the forces generated are a combination of the cutting of the two different materials. This was also found to be the reason why the rate of change of the cutting forces as a result of toolworkpiece engagement and disengagement is larger with 
Fig. 7 Cutting forces generated by the assessed tool geometries

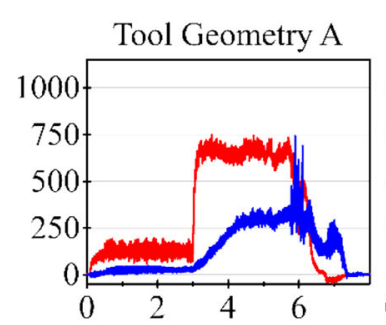

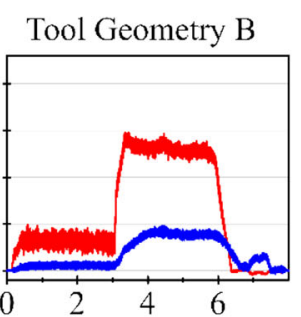

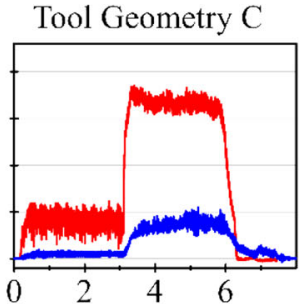

Tool Geometry D

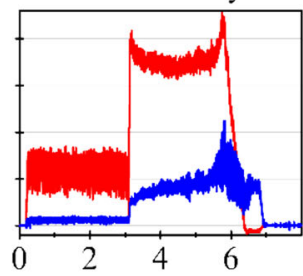

Time $[\mathrm{s}]$
Thrust [N]

Torque $[\mathrm{Ncm}]$ an increase in drill point angle. When using tools $\mathrm{D}$ and - to a lesser extent - tools B and C, the thrust force exhibits its highest amplitude during the initial engagement with the titanium layer, after which it gradually decreases. This can be explained by the untwisting of the tool during initial engagement with the workpiece through the chisel edge, which results in a slight elongation and, thus, a sudden increase in thrust force [36]. This is then followed by a slight relaxation as a result of the system comprising tool, workpiece and machine tool reaching equilibrium, bringing with it a shortening of the drilling tool and, consequently, drop in thrust force [37]. Another factor that will have contributed to the reduction in thrust force is the increase in cutting temperature with an increase in drilling depth, leading to thermal softening of the titanium, as suggested by Zeilmann and Weingaertner [38].

Cutting of the CFRP was characterised by strong fluctuations in the thrust force, which is attributable to the stacked nature of the material. This can be explained by considering the interfaces between adjacent plies as soft spots. The engagement of the tool tip with these soft spots results in an instantaneous decrease in the thrust force, as the tool tip moves from one unidirectional ply to the next. The results obtained from this research suggest that there is a relationship between the tool point angle and the extent of which the thrust force fluctuates whilst the drill is penetrating through the CFRP material, inasmuch as the amplitude of these fluctuations was higher for tools with larger point angles. This can be explained by the fact that the point angle dictates the number of ply interfaces (i.e. soft spots) that the tool tip is engaged with at any one time. In the case of tools $\mathrm{D}\left(180^{\circ}\right.$ point angle $)$ the tip is engaged with only one single ply interface, whereas the tip of tool $\mathrm{A}\left(118^{\circ}\right.$ point angle, resulting in a tip height of approximately $1.8 \mathrm{~mm}$ ) is simultaneously engaged with up to 7 plies.

In order to substantiate this claim, the thrust force signals recorded during a period of the drilling cycle where the tool tip was fully engaged in the composite material were analysed in the frequency domain, by conducting a fast Fourier transform. The results of this are shown in Fig. 8a, looking at a frequency range of 0 to $200 \mathrm{~Hz}$, and Fig. $8 \mathrm{~b}$, which zooms in to a range around the dominant peak at $14 \mathrm{~Hz}$, which is the ply engagement frequency. This corresponds to a period of $0.07 \mathrm{~s}$ that is equal to the time taken for the drill to move through one CFRP ply (thickness $0.254 \mathrm{~mm})$ with the feed velocity employed $(215 \mathrm{~mm} /$ min). The curves in Fig. 8b clearly show that the tools with the largest point angle (i.e. tool D, $180^{\circ}$ ) caused the strongest fluctuation of the thrust force, followed by tool $\mathrm{C}$ $\left(150^{\circ}\right)$, and then tools $\mathrm{B}\left(140^{\circ}\right)$ and $\mathrm{A}\left(118^{\circ}\right)$. However, it is pertinent to note that tool B actually showed slightly smaller fluctuations at the frequency of interest (i.e. $14 \mathrm{~Hz}$ ) despite possessing a larger point angle compared with tool A. The reason for this is yet not fully understood, but could be attributable to the difference in point geometry (4-facet with notches in the case of tools A; 6-facet in the case of tool B). Nonetheless, considering the time-domain, the
Fig. 8 Thrust force signal frequency-domain analysis; a 0 $200 \mathrm{~Hz}$ spectrum, b $10-18 \mathrm{~Hz}$ spectrum

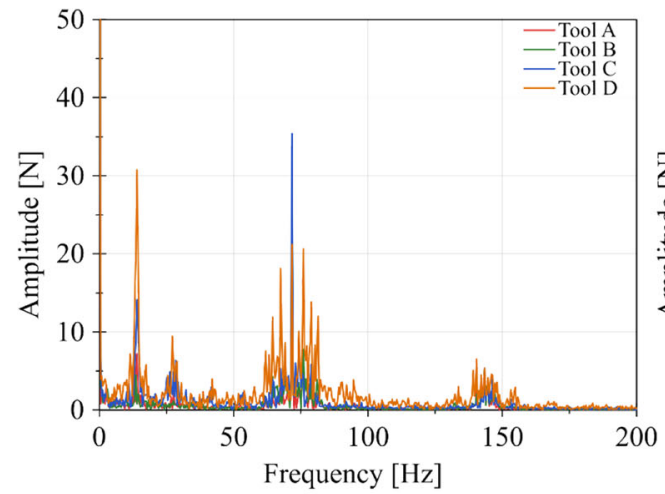

a

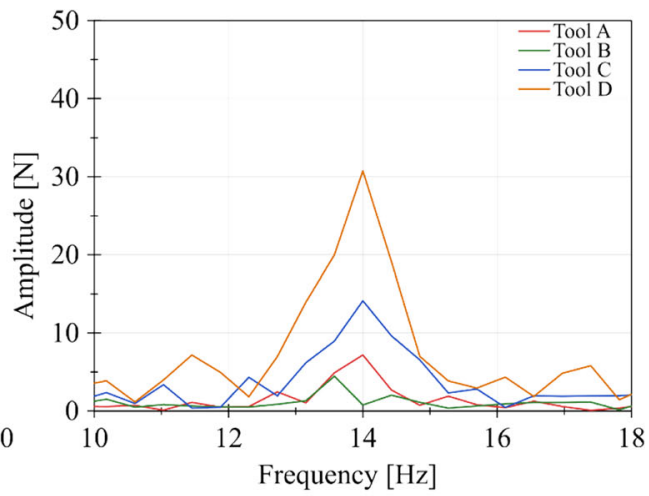

b 


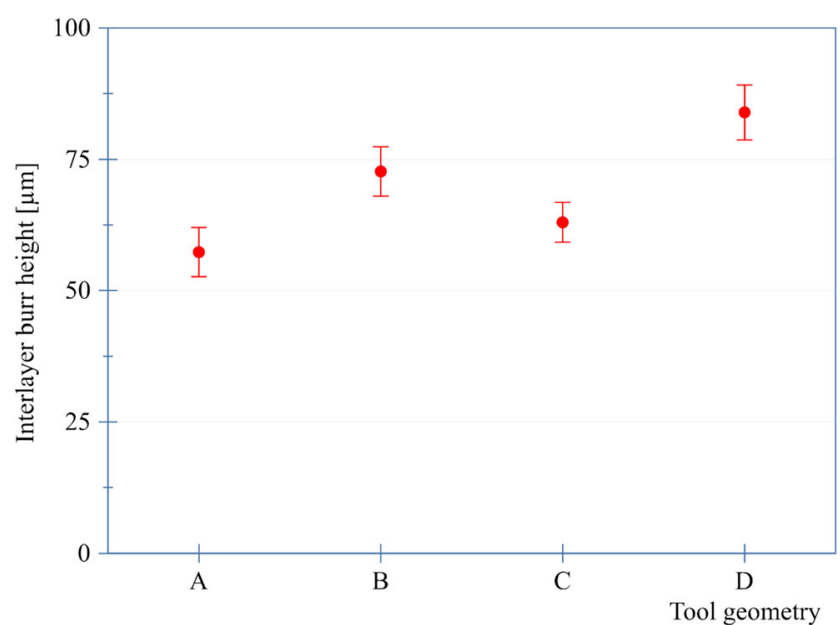

Fig. 9 Average entry interlayer burr on the top surface of the bottom titanium layer

amplitude of the thrust force fluctuations follow the abovementioned trend, with the increase in point angle resulting in an increase in thrust force fluctuations.

\subsection{Influence of tool point angle on titanium interface quality}

Measuring the height of the entry interlayer burr on the top surface of the titanium layer revealed average values ranging from 57 to $84 \mu \mathrm{m}$, see Fig. 9. It was observed that, overall, an increase in tool point angle brings about an increase in entry interlayer burrs. A possible explanation for this is that during material engagement, the sudden rise in thrust force is more pronounced for tools with larger point angles, as for a given increment in the axial direction, a larger radial portion of the tool tip is fed into the material. In other words, the tool tip plunges into the material more suddenly, whereas for a tool with a smaller point angle, this engagement happens more progressively. The larger the thrust force during tool entry, the more plastic deformation will take place in the material directly underneath the tool tip, thereby resulting in the formation of larger burrs. Furthermore, some degree of tool skidding is likely to take place during material transition, when the chisel edge breaks through the CFRP and pushes against the upper surface of the titanium layer. In the case of a drill with a small point angle $\left(118^{\circ}\right)$, the damage resulting from tool skidding is rectified as the cutting edges get progressively engaged with the workpiece and thereby remove initial damage that may have been formed (including burrs). As the point angle increases, the capability of the tool tip to remove previous damage diminishes, because the distance the tool travels in axial direction between initial engagement and when the cutting edges are fully engaged decreases, to the point that in the case of tool geometry $\mathrm{D}\left(180^{\circ}\right)$, the entire tool tip gets engaged at once. The consequence of this is that any damage that was caused during initial tool engagement could not be removed by subsequent portions of the tool's tip, which explains why the tools with a point angle of $180^{\circ}$ produced significantly larger burrs compared with the other tools investigated.

The measurements of the entry and exit borehole diameters, see Fig. 10a, appear to be related to the tool point angle, so much so that an increase in tool point angle results in an increase in borehole diameter. This can be explained by the findings made by Spur [37], who observed that the not perfectly symmetrical geometry of drilling tools resulted in the formation of a small radial force, which led to the bending and, consequently, tumbling of the drilling tool. This in turn caused an increase in the diameter of the boreholes produced. As alluded to before, an increase in tool point angle results in larger thrust forces, which will further contribute to the radial force caused by the asymmetry of the tool, thereby leading to more pronounced tumbling of the tool, resulting in larger borehole diameters. Except for tool B, where the entry diameter was slightly smaller than the exit diameter, all other tools created boreholes that exhibited a smaller entry than exit diameter. This can be explained by the fact that despite tungsten carbide having a similar coefficient of thermal expansion as titanium, its thermal conductivity is almost ten times higher. As a consequence, the tool heats up and expands more rapidly than the surrounding titanium whilst it progresses through the material and, thus, produces holes of increasingly larger diameter. The relatively longer chisel edge in the case of tools B will have caused more pronounced skidding during tool entry
Fig. 10 Borehole diameter (a) and surface roughness (b) of titanium layer for different tool geometries

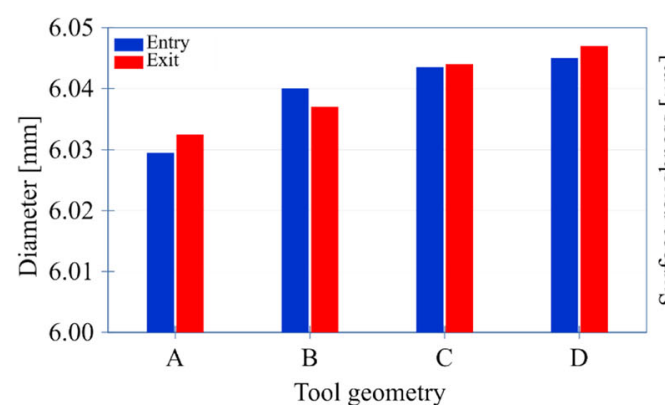

a

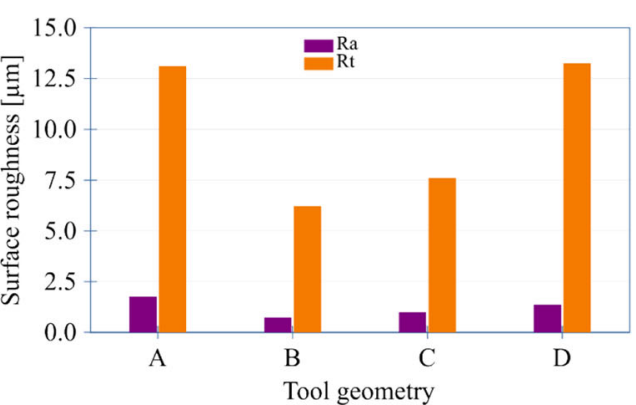

b 
as compared with the other tool geometries, which explains the larger entry than exit diameter, an observation that is in agreement with Heinemann [39].

The lowest surface roughness, quantified by the arithmetic mean roughness $R_{\mathrm{a}}$ and total height of roughness profile $R_{\mathrm{t}}$, of the boreholes drilled into the titanium layer was produced with tool B and, to a slightly lesser extent, tools C, see Fig. 10b. In contrast, tools A and D resulted in substantially higher surface roughness values. These results correlate with the dynamics of the recorded cutting torque, shown in Fig. 7, in so much as larger oscillations in the torque signal coincide with an increased surface roughness. The correlation between oscillations in the torque signal and surface roughness can be explained by the occurrence of substantial chip clogging, as observed in the case of tools $\mathrm{A}$ and $\mathrm{D}$, which causes the drilling process to become increasingly unstable, resulting in a deterioration of the surface finish. Tool B instead exhibited the most stable cutting process, brought about by the most steady chip evacuation, as shown by the small dynamic component in both the thrust force and torque, and thus produced the boreholes with the smallest surface roughness.

\subsection{Influence of interlayer gap size on interface quality}

Photographic images of the interface CFRP surface around the borehole after drilling with different pre-set interlayer gap widths are shown in Fig. 11. These show a ring of damage, similar to a corona, along the borehole's edge, characterised by erosion of the CFRP. With an increase in interlayer gap width, this damage ring increases in width, from approximately $0.5 \mathrm{~mm}$ in the case of the smallest interlayer gap $(0.05 \mathrm{~mm})$ to around $3 \mathrm{~mm}$ when drilling a stack with an interlayer gap width of 0.3 $\mathrm{mm}$. This erosive damage on the CFRP layer is the result of some of the upwards-travelling hot titanium chips penetrating the interlayer gap and then being spun around by the rotating tool. Increasing the interlayer gap width eases the ingress of titanium chips into the stack interface, allowing a growing amount of chips to accumulate between the two layers, thus leading to more pronounced damage as they scrape over the surface. These findings are in agreement with the observations made by Pardo et al. [24] when drilling aluminium/ aluminium stacks. The aforementioned damage due to abrasion is further exacerbated by the CFRP's low degradation temperature, which is approximately $160^{\circ}-200^{\circ}$ $[34,40]$ and, as such, significantly lower than the cutting temperatures typically found when drilling titanium, which depending on the cutting parameters vary between $400^{\circ}$ and $800^{\circ}[38,41,42]$. With the cutting temperature this high, it is reasonable to assume that the temperature of the titanium chips is still significantly higher than the CFRP's degradation temperature.

It is pertinent to note that the chip flow in drilling is considered as a stochastic process [43], meaning that the variation in chip flow, and with it the overall process stability, can vary considerably between drilling cycles despite the process-defining parameters remaining unchanged. For this research, as a consequence, it means that the variation in interface quality observed between samples drilled with identical experimental parameters at times was quite significant. For example, Fig. 12 shows two boreholes drilled into a stack with a $0.1 \mathrm{~mm}$ pre-set interlayer gap width. While the borehole on the left represents what is considered to be a typical interlayer surface for this tool operating with the set parameters - based on a large number of boreholes - the borehole on the right exhibits significantly greater surface damage. This is believed to have been caused by chip jamming inside the tool's flutes, resulting not only in a greater amount of chips being pushed into the stack interface and causing abrasion, but also a larger amount of heat having migrated into the surrounding CFRP layer, further promoting heatrelated damage. Variations in borehole quality between tests carried out with the same experimental conditions were observed more frequently in the case of larger interlayer gaps, which is understandable as larger interlayer gaps make it easier for chips to penetrate into the interface. These chips then further disrupt the chip flow,
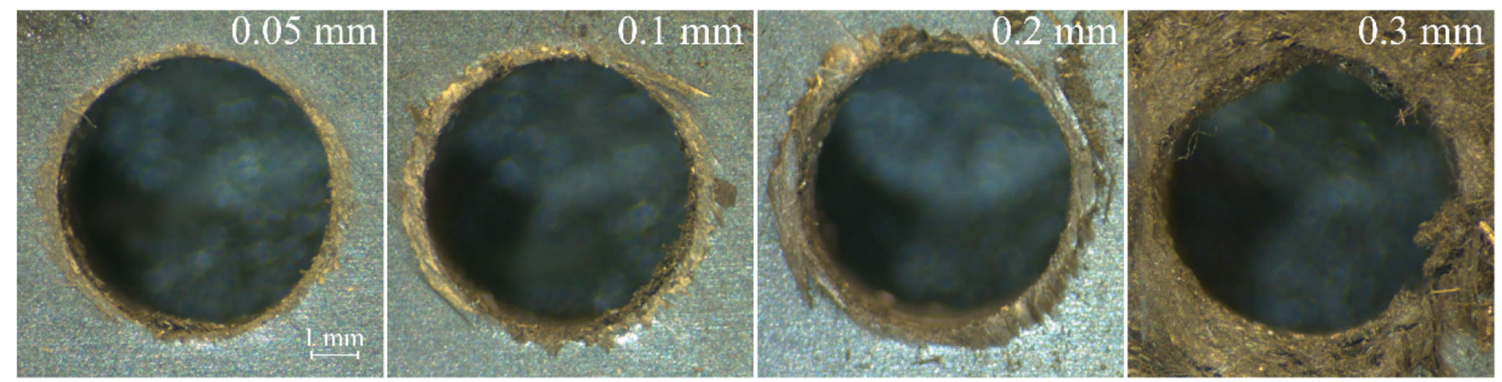

Fig. 11 CFRP interface damage for different interlayer gaps 


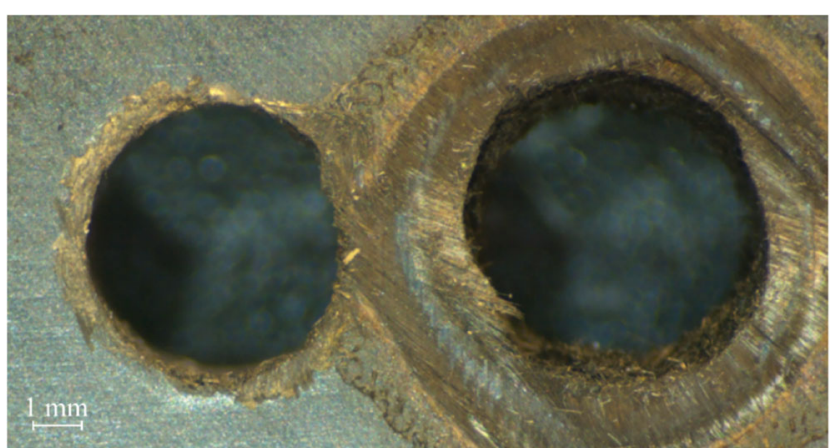

Fig. 12 Variation in CFRP interlayer surface damage within two boreholes drilled with the same parameters

causing a chain reaction, leading to additional chip clogging and yet more chips being pushed into the interface, ultimately resulting in further workpiece damage.

Although some noticeable differences in average entry interlayer burr height were recorded on the titanium layer in relation to the pre-set interlayer gap width, as shown in Fig. 13, a clear trend between interlayer gap width and burr height cannot be identified. Drilling a stack without or with only a very small interlayer gap $(0.05 \mathrm{~mm})$ resulted in the largest burr, whereas the introduction of a gap of at least $0.1 \mathrm{~mm}$ caused the burr height to be reduced considerably. When drilling aluminium/aluminium stacks, Pardo et al. [24] noticed that chip ingress in the stack interface was found to result in abrasion of the borehole edges, leading not only to the complete removal of the exit interlayer burr, but also some reduction of the entry interlayer burr height. The use of titanium as the bottom layer in the case of this research might explain why the extensive erosion observed by Pardo et al. [24] did not take place, due to its significantly higher strength and hardness as compared with aluminium. In other words, the entry burrs formed were strong enough to withstand excessive erosion and, thus, did not get completely abraded by the upwards-

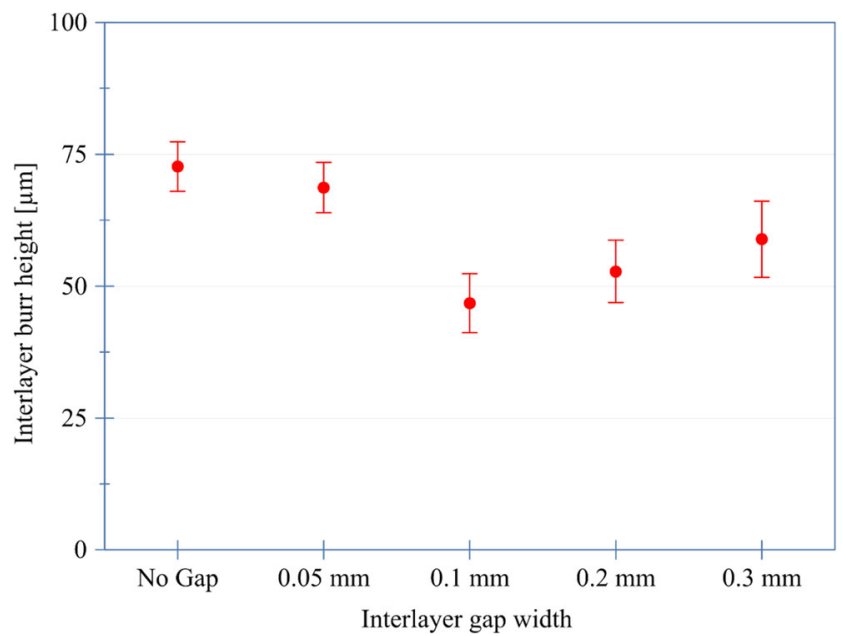

Fig. 13 Entry interlayer burr height in titanium for different pre-set interlayer gaps travelling chips. Further research, however, is required to allow for a more in-depth assessment of the correlation between interlayer gap width and interlayer burr formation when drilling stacks comprising titanium layers.

\section{Conclusions}

In this research work, the influence of tool point angle and interlayer gap width on interlayer borehole quality when drilling CFRP/titanium stacks has been investigated. Based on the results obtained, the following conclusions can be drawn:

- The damage on the CFRP interlayer surface is not caused by the actual cutting of the CFRP, but instead caused by the drilling of the titanium layer below. This damage can be attributed to the upwards-travelling titanium chips and heat accumulation in the tool and the stack interface. Tools exhibiting a fairly stable titanium cutting process and chip evacuation were thus found to produce significantly better boreholes than tools that were found to exhibit - on average - a less smooth chip flow and, as a consequence, poorer process stability.

- In the titanium interlayer surface, an increase in tool point angle results in larger entry burrs. This is due to the positive correlation between tool point angle and thrust force, as well as the increased capability of tools with low point angles to remove damage generated by surface skidding during initial tool entry.

- The introduction of a pre-set interlayer gap promotes the ingress of upwards-travelling titanium chips into the stack interface, thereby leading to extensive abrasive and thermal damage of the CFRP interlayer surface. The wider the interlayer gap, the easier it becomes for titanium chips to penetrate the interface and, consequently, the greater the composite interlayer damage.

- Although the introduction of a pre-set interlayer gap appears to result in a slight reduction in the entry interlayer burr in the titanium layer, caused by the abrasion of upwards travelling titanium chips, a clear relationship between interlayer gap width and interlayer burr formation in the titanium surface cannot be established. Further research therefore needs to be conducted in order to be able to shed more light onto this aspect.

Acknowledgements This project was supported by Airbus UK, who provided the workpiece material used for the cutting experiments. Their contribution is kindly acknowledged. The authors would also like to acknowledge the contribution made by $\mathrm{Ms} \mathrm{Ye} \mathrm{He}(\mathrm{MSc})$, who conducted a number of the experiments reported on in this paper.

Availability of data and material Data can be made available upon request subject to approval of all parties involved in the research. 
Code availability Not applicable.

Author contribution Conceptualization, Andrea Pardo (A.P.), Julie Le Gall (J.L.G.), Robert Heinemann (R.H.), Luke Bagshaw (L.B.); methodology, A.P., J.L.G., R.H.; software, A.P., J.L.G.; validation, A.P., J.L.G., R.H.; formal analysis, A.P., J.L.G.; investigation, A.P., J.L.G., R.H.; resources, A.P., J.L.G., R.H., L.B.; data curation, A.P.; writing, A.P., J.L.G., R.H.; visualization, A.P.; supervision, R.H.; project administration, A.P., R.H., L.B.; funding acquisition, N/A.

Funding This research did not receive any specific grant from funding agencies in the public, commercial or not-for-profit sectors.

\section{Declarations}

Ethical approval No ethical approval was required for this research.

\section{Consent to participate N/A.}

Consent for publication All authors have read and agreed to the published version of the manuscript.

Competing interests The authors declare that they have no competing interests.

Open Access This article is licensed under a Creative Commons Attribution 4.0 International License, which permits use, sharing, adaptation, distribution and reproduction in any medium or format, as long as you give appropriate credit to the original author(s) and the source, provide a link to the Creative Commons licence, and indicate if changes were made. The images or other third party material in this article are included in the article's Creative Commons licence, unless indicated otherwise in a credit line to the material. If material is not included in the article's Creative Commons licence and your intended use is not permitted by statutory regulation or exceeds the permitted use, you will need to obtain permission directly from the copyright holder. To view a copy of this licence, visit http://creativecommons.org/licenses/by/4.0/.

\section{References}

1. Denkena B, Boehnke D, Dege JH (2008) Helical milling of CFRPtitanium layer compounds. CIRP J Manuf Sci Technol 1:64-69. https://doi.org/10.1016/j.cirpj.2008.09.009

2. Xu J, El Mansori M, Chen M, Ren F (2019) Orthogonal cutting mechanisms of CFRP/Ti6A14V stacks. Int J Adv Manuf Technol 103:3831-3851. https://doi.org/10.1007/s00170-019-03734-x

3. Sorrentino L, Turchetta S, Bellini C (2017) In process monitoring of cutting temperature during the drilling of FRP laminate. Compos Struct 168:549-561. https://doi.org/10.1016/j.compstruct.2017.02. 079

4. Krishnamoorthy A, Lilly Mercy J, Vineeth KSMM, Salugu MK (2015) Delamination analysis of carbon fiber reinforced plastic (CFRP) composite plates by thermo graphic technique. Mater Today Proc 2:3132-3139. https://doi.org/10.1016/j.matpr.2015. 07.101

5. Davim JP, Rubio JC, Abrao AM (2007) A novel approach based on digital image analysis to evaluate the delamination factor after drilling composite laminates. Compos Sci Technol 67:1939-1945. https://doi.org/10.1016/j.compscitech.2006.10.009
6. Sharif S, Rahim EA (2007) Performance of coated- and uncoatedcarbide tools when drilling titanium alloy-Ti-6Al4V. J Mater Process Technol 185:72-76. https://doi.org/10.1016/j.jmatprotec. 2006.03.142

7. Xu J, El Mansori M (2016) Experimental studies on the cutting characteristics of hybrid CFRP/Ti stacks. Procedia Manuf 5:270 281. https://doi.org/10.1016/j.promfg.2016.08.024

8. Isbilir O, Ghassemieh E (2012) Delamination and wear in drilling of carbon-fiber reinforced plastic composites using multilayer TiAlN/TiN PVD-coated tungsten carbide tools. J Reinf Plast Compos 31:717-727. https://doi.org/10.1177/0731684412444653

9. Wang X, Kwon PY, Sturtevant C, Kim D(DW), Lantrip J (2014) Comparative tool wear study based on drilling experiments on CFRp/Ti stack and its individual layers. Wear 317:265-276. https://doi.org/10.1016/j.wear.2014.05.007

10. Fernández-Pérez J, Cantero JL, Díaz-Álvarez J, Miguélez MH (2017) Influence of cutting parameters on tool wear and hole quality in composite aerospace components drilling. Compos Struct 178:157-161. https://doi.org/10.1016/j.compstruct.2017.06.043

11. Xu J, El Mansori M (2016) Experimental study on drilling mechanisms and strategies of hybrid CFRP/Ti stacks. Compos Struct 157: 461-482. https://doi.org/10.1016/j.compstruct.2016.07.025

12. Xu J, Li C, Chen M, Ren F (2019) A comparison between vibration assisted and conventional drilling of CFRP/Ti6A14V stacks. Mater Manuf Process 34:1182-1193. https://doi.org/10.1080/10426914. 2019.1615085

13. Li C, Xu J, Chen M, An Q, el Mansori M, Ren F (2019) Tool wear processes in low frequency vibration assisted drilling of CFRP/ Ti6Al4V stacks with forced air-cooling. Wear 426-427:16161623. https://doi.org/10.1016/j.wear.2019.01.005

14. Alonso U, Calamaz M, Girot F, Iriondo E (2019) Influence of flute number and stepped bit geometry when drilling CFRP/Ti6Al4V stacks. J Manuf Process 39:356-370. https://doi.org/10.1016/j. jmapro.2019.02.006

15. Xu J, Ji M, Chen M, Ren F (2019) Investigation of minimum quantity lubrication effects in drilling CFRP/Ti6Al4V stacks. Mater Manuf Process 34:1401-1410. https://doi.org/10.1080/ 10426914.2019.1661431

16. Kuo CL, Soo SL, Aspinwall DK, Carr C, Bradley S, M'Saoubi R, Leahy W (2018) Development of single step drilling technology for multilayer metallic-composite stacks using uncoated and PVD coated carbide tools. J Manuf Process 31:286-300. https://doi.org/10. 1016/j.jmapro.2017.11.026

17. Xu J, Mkaddem A, El Mansori M (2016) Recent advances in drilling hybrid FRP/Ti composite: a state-of-the-art review. Compos Struct 135:316-338. https://doi.org/10.1016/j.compstruct.2015.09. 028

18. Abrão AM, Rubio JCC, Faria PE, Davim JP (2008) The effect of cutting tool geometry on thrust force and delamination when drilling glass fibre reinforced plastic composite. Mater Des 29:508 513. https://doi.org/10.1016/j.matdes.2007.01.016

19. Campos Rubio J, Abrao AM, Faria PE, Correia AE, Davim JP (2008) Effects of high speed in the drilling of glass fibre reinforced plastic: evaluation of the delamination factor. Int $\mathrm{J}$ Mach Tools Manuf 48:715-720. https://doi.org/10.1016/j.ijmachtools.2007.10. 015

20. Davim JP, Reis P, António CC (2004) Experimental study of drilling glass fiber reinforced plastics (GFRP) manufactured by hand lay-up. Compos Sci Technol 64:289-297. https://doi.org/10.1016/ S0266-3538(03)00253-7

21. Davim JP, Reis P (2003) Study of delamination in drilling carbon fiber reinforced plastics (CFRP) using design experiments. Compos Struct 59:481-487. https://doi.org/10.1016/S0263-8223(02)00257$\mathrm{X}$

22. Gaitonde VN, Karnik SR, Rubio JC, Correia AE, Abrão AM, Davim JP (2008) Analysis of parametric influence on delamination 
in high-speed drilling of carbon fiber reinforced plastic composites. J Mater Process Technol 203:431-438. https://doi.org/10.1016/j. jmatprotec.2007.10.050

23. Heisel U, Pfeifroth $T$ (2012) Influence of point angle on drill hole quality and machining forces when drilling CFRP. Procedia CIRP 1:471-476. https://doi.org/10.1016/j.procir.2012.04.084

24. Pardo A, Cseke A, Heinemann R, Whiffen R (2019) The effect of interlayer gap width on burr formation in drilling of aluminiumaluminium aerospace stacks. Int J Adv Manuf Technol 104:30353043. https://doi.org/10.1007/s00170-019-04202-2

25. Gao Y, Wu D, Nan C, Ma X, Dong Y, Chen K (2015) The interlayer gap and non-coaxiality in stack drilling. Int J Mach Tools Manuf 99:68-76. https://doi.org/10.1016/j.ijmachtools.2015.09. 007

26. Tian W, Hu J, Liao W, Bu Y, Zhang L (2016) Formation of interlayer gap and control of interlayer burr in dry drilling of stacked aluminum alloy plates. Chin J Aeronaut 29:283-291. https:/doi. org/10.1016/j.cja.2015.11.002

27. Yin B, Wei T, WenHe L et al (2015) Investigation of correlation between interlayer gap and burr height in drilling of stacked Al7475 materials. Proc Inst Mech Eng Part B J Eng Manuf:1-14. https://doi.org/10.1177/0954405415617671

28. Melkote SN, Newton TR, Hellstern C et al (2010) Interfacial burr formation in drilling of stacked aerospace materials. In: Aurich JC, Dornfeld D (eds) Burrs - Analysis, Control and Removal. Springer Berlin Heidelberg, Berlin, pp 89-98

29. Jie L (2013) The formation and effect of interlayer gap in dry drilling of stacked metal materials. Int J Adv Manuf Technol 69:12631272. https://doi.org/10.1007/s00170-013-5112-9

30. Shyha ISS, Soo SLL, Aspinwall DKK et al (2011) Hole quality assessment following drilling of metallic-composite stacks. Int $\mathrm{J}$ Mach Tools Manuf 51:569-578. https://doi.org/10.1016/j. ijmachtools.2011.04.007

31. Ramulu M, Branson T, Kim D (2001) A study on the drilling of composite and titanium stacks. Compos Struct 54:67-77. https:// doi.org/10.1016/S0263-8223(01)00071-X

32. Isbilir O, Ghassemieh E (2013) Comparative study of tool life and hole quality in drilling of CFRP/titanium stack using coated carbide drill. Mach Sci Technol 17:380-409. https://doi.org/10.1080/ 10910344.2013.806098

33. Ramirez C, Poulachon G, Rossi F, M'Saoubi R (2014) Tool wear monitoring and hole surface quality during CFRP drilling. Procedia CIRP 13:163-168. https://doi.org/10.1016/j.procir.2014.04.028
34. Fu R, Jia Z, Wang F, Jin Y, Sun D, Yang L, Cheng D (2018) Drillexit temperature characteristics in drilling of UD and MD CFRP composites based on infrared thermography. Int J Mach Tools Manuf 135:24-37. https://doi.org/10.1016/j.ijmachtools.2018.08. 002

35. Brinksmeier E, Janssen R (2002) Drilling of multi-layer composite materials consisting of carbon fiber reinforced plastics (CFRP), titanium and aluminum alloys. CIRP Ann - Manuf Technol 51: 87-90. https://doi.org/10.1016/S0007-8506(07)61472-3

36. Hoff M (1986) Analyse und Optimierung des Bohrprozesses. University of Aachen, Aachen

37. Spur G (1961) Beitrag zur Schnittkraftmessung beim Bohren mit Spiralbohrern unter Berücksichtigung der Radialkräfte. University of Braunschweig, Braunschweig

38. Zeilmann RP, Weingaertner WL (2006) Analysis of temperature during drilling of Ti6Al4V with minimal quantity of lubricant. J Mater Process Technol 179:124-127. https://doi.org/10.1016/j. jmatprotec.2006.03.077

39. Heinemann RK (2012) The effect of starting hole geometry on borehole quality and tool life of twist drills. Int J Adv Manuf Technol 60:519-526. https://doi.org/10.1007/s00170-011-3625-7

40. Merino-Pérez JL, Royer R, Merson E, Lockwood A, AyvarSoberanis S, Marshall MB (2016) Influence of workpiece constituents and cutting speed on the cutting forces developed in the conventional drilling of CFRP composites. Compos Struct 140: 621-629. https://doi.org/10.1016/j.compstruct.2016.01.008

41. Patne HS, Kumar A, Karagadde S, Joshi SS (2017) Modeling of temperature distribution in drilling of titanium. Int J Mech Sci 133: 598-610. https://doi.org/10.1016/j.ijmecsci.2017.09.024

42. Lazoglu I, Poulachon G, Ramirez C, Akmal M, Marcon B, Rossi F, Outeiro JC, Krebs M (2017) Thermal analysis in Ti-6Al-4V drilling. CIRP Ann - Manuf Technol 66:105-108. https://doi.org/10. 1016/j.cirp.2017.04.020

43. Mathew NT, Vijayaraghavan L (2016) Drilling of titanium aluminide at different aspect ratio under dry and wet conditions. J Manuf Process 24:256-269. https://doi.org/10.1016/j.jmapro. 2016.09.009

Publisher's note Springer Nature remains neutral with regard to jurisdictional claims in published maps and institutional affiliations. 